\title{
An Asthma Action Plan Created by Physician, Educator and Patient Online Collaboration with Usability and Visual Design Optimization
}

\author{
Samir Gupta ${ }^{a-c}$ Flora T. Wan ${ }^{b}$ Susan E. Hall ${ }^{b}$ Sharon E. Straus ${ }^{a, b}$ d \\ ${ }^{a}$ Department of Medicine, University of Toronto, ${ }^{b}$ The Keenan Research Centre in the Li Ka Shing Knowledge \\ Institute, and Divisions of ${ }^{\mathrm{c}}$ Respirology and ${ }^{\mathrm{d}}$ Geriatrics, Department of Medicine, St. Michael's Hospital, \\ Toronto, Ont., Canada
}

\section{Key Words}

Asthma action plan $\cdot$ Primary care $\cdot$ User-computer interface $\cdot$ Self-management

\begin{abstract}
Background: Asthma action plans (AAPs), which decrease hospitalizations and improve symptom control, are recommended in guidelines, but are seldom delivered to patients. Existing AAPs have been developed by experts, without the inclusion of all stakeholders (such as patients with asthma) and without specifically addressing usability and visual design. Objective: Our objective was to develop a more usable AAP by involving all stakeholders and considering design preferences. Methods: We created a Wiki-based system for multiuser AAP development. Pulmonologists, primary care physicians, asthma educators and patients used the system to collaboratively compile a single AAP by making multiple online selections over 1 week. We combined common elements from 3 AAPs developed in this way into 1, optimized visual design features and tested face validity in focus groups. Results: A total of 41 participants averaged 646 selections/week over a login-time of $28.8 \mathrm{~h} /$ week. Of 35 participants, $28(80 \%)$ were satisfied with the final AAP and 32 (91\%) perceived that they would be able to use it. The plans
\end{abstract}

\begin{tabular}{ll}
\hline KARGER & $\begin{array}{l}\text { ( 2012 S. Karger AG, Basel } \\
0025-7931 / 12 / 0845-0406 \$ 38.00 / 0 \quad \text { Karger }\end{array}$ \\
E-Mail karger@karger.ch & This is an Open Access article licensed under the terms of \\
www.karger.com/res & $\begin{array}{l}\text { the Creative Commons Attribution- NonCommercial-No- } \\
\text { Derivs 3.0 License (www.karger.com/OA-license), applica- } \\
\text { ble to the online version of the article only. Distribution for } \\
\text { non-commercial purposes only. }\end{array}$
\end{tabular}

created by the 3 groups were very similar, with a unanimous or majority agreement in the handling of 100/110 (91\%) AAP options. Conclusions: Inclusion of multiple stakeholders and focus on design preferences predict enhanced usability and uptake of medical tools. The validity of our AAP is further supported by the similarity between the AAPs created by each group, user engagement and satisfaction with the plan and agreement with existing validity criteria proposed by experts. This AAP can be implemented in care with a concurrent measurement of uptake and health impact.

Copyright $\odot 2012$ S. Karger AG, Basel

\section{Background}

An asthma action plan (AAP) is an individualized written plan produced by a health care professional (HCP) for a patient with asthma, for the purpose of providing education and guidelines for the self-management of worsening asthma symptoms [1]. A systematic review of randomized controlled trials (RCTs) demonstrated that, in conjunction with education and regular clinical review, a written AAP significantly reduces hospitalizations, emergency room and unscheduled doctor visits, missed work or school and symptoms, and significantly improves

Dr. Samir Gupta

Suite 6045, Bond Wing

30 Bond St.

Toronto, ON M5B 1W8 (Canada)

Tel. +1 416864 6026, E-Mail guptas@smh.ca 
quality of life [1]. The National Heart, Lung and Blood Institute Guidelines for the Diagnosis and Management of Asthma recommend that all patients receive a written AAP [2]. However, AAP usage has been shown to be low across countries; in Canada, only $22 \%$ of physicians reported providing a written AAP, and only $11 \%$ of patients reported receiving one [3]. Barriers to delivery of AAPs by HCPs include a lack time, a lack of experience and confidence in generating appropriate AAP recommendations and concerns regarding patient adherence [4-9].

Most existing AAPs have been developed through informal consensus techniques, by development teams consisting exclusively of medical experts. Furthermore, these experts have focused on AAP content without addressing usability and visual design factors [10]. However, multiple stakeholder engagement in the development process has been shown to be a key determinant of the implementability of evidence summaries [11], guidelines [12] and patient tools $[13,14]$. In addition, basic human factors design elements such as font size and type and paragraph and page layout influence the visual appeal of media intended for health care interventions and also predict their effectiveness $[15,16]$. Incorporating these elements into AAP design could address AAP delivery barriers by optimizing usability [17]. Accordingly, we sought to develop an adult AAP through a process that (1) included the HCPs that commonly deliver AAPs [primary care physicians (PCPs) and certified asthma educators] as well as patients with asthma (who are the end-users) and (2) elicited and incorporated the preferences of these users for the visual design of the AAP.

Conventional in-person interactive consensus techniques are susceptible to bias (due to social hierarchies between stakeholders, e.g. professionals and patients) [18] and are poorly suited for visual design (due to difficulties inherent in the verbal expression of aesthetic preferences) $[18,19]$. Accordingly, we conceived a novel Wiki-based methodology to achieve group consensus. A Wiki is a web-based collaborative software that not only allows users to add content online, but also to alter existing content according to their preferences. This medium enables the accurate and dynamic representation of visual characteristics while maintaining participant anonymity.

\section{Methods}

Our methodology included a development stage, a Wiki stage, a plan amalgamation stage, a human factors correction stage and a face validation stage, as follows.

\section{Development Stage}

In order to accurately reflect design permutations ('format') and the interaction between content and format, we designed the site such that users could construct and view the AAP in 'realtime,' as they navigated a series of choices presented in drop-down menus (fig. 1). Details of the software development process have been described elsewhere [20]. The study protocol and consent forms were approved by our Institutional Review Board. Development occurred in 4 stages. First, we established content and format permutations to include in the system, using the following sources: (1) medical and human factors literature reviews for content and format elements, respectively, (2) a catalog of previously used content and format elements based on a review of 69 adult AAPs and (3) the opinion of asthma experts and human factors design experts for content and format elements, respectively. Second, we iteratively designed a web-based system capable of representing each of these content and format permutations, with serial testing by research-team members. Third, we tested this in a series of moderated focus groups and interviews involving participants from each of the key stakeholder groups, recruited purposely to reflect both academic and community practice settings. We recruited pulmonologists, asthma educators, patients and PCPs from a quaternary-care university-based hospital (St. Michael's Hospital), and PCPs and patients from community clinics within the Greater Toronto Area. Inclusion criteria included a self-reported physician diagnosis of asthma (for patients) and adequate computer skills as determined by a brief screening questionnaire (for all participants) (see online supplementary file 1 ; for all online supplementary material, see www.karger.com/ doi/10.1159/000338112). All participants completed brief background questionnaires. Fourth, we analyzed user feedback and revised the tool in order to optimize content and format choices and system usability.

\section{Wiki Stage}

We utilized the revised tool for AAP development in a Wiki environment. We created 3 groups of new users, each comprising 14 participants ( 3 pulmonologists, 2 PCPs, 2 asthma educators and 7 asthma patients), purposely sampled to reflect a broad range of geographical settings and practice environments. We recruited HCPs from academic and community clinics in Canada, academic centers in the USA and Australia, a Canadian Asthma Action Plan Workshop (held in March, 2008) and the Ontario Lung Association. We recruited patients from academic and community clinics within the Greater Toronto Area and through the Asthma Society of Canada. Patients required a self-reported physician diagnosis of asthma, and all participants had to fulfill the requirements listed in the online supplementary file 1 as well as the following: (1) access to high-speed internet at work or at home, (2) an average of $\geq 4 \mathrm{~h}$ weekly internet use at work or home and (3) use at least once-weekly of at least 3 of the following applications: e-mail, Internet Explorer ${ }^{\mathrm{TM}}$, Mozilla Firefox ${ }^{\mathrm{TM}}$, Apple Safari ${ }^{\mathrm{TM}}$, Microsoft Word/Excel/Powerpoint ${ }^{\mathrm{TM}}$, and Adobe PDF ${ }^{\mathrm{TM}}$. All participants completed brief background questionnaires.

Each group was given a 1 week during which members collaboratively authored a single, printable AAP by making multiple selections in the online tool (available at: http://knowledgetranslation.ca/octapus/) (please use the Safari ${ }^{\mathrm{TM}}$ web-browser). During this period, the tool functioned as a Wiki, whereby any member could log in at any time and alter choices made by other members. 


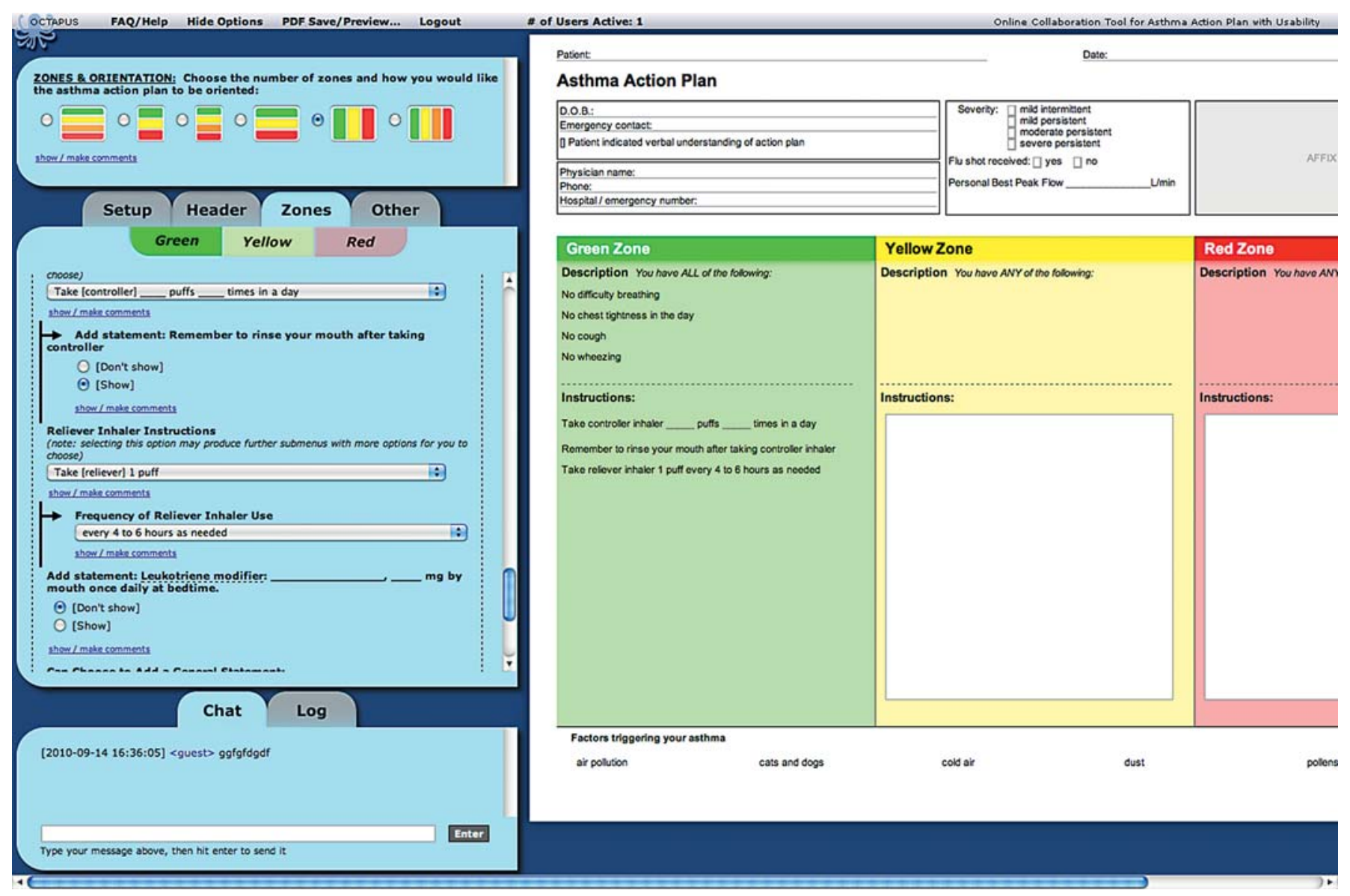

Fig. 1. A screenshot of the Wiki tool, demonstrating drop-down menus on the left- hand side and the dynamic AAP on the right-hand side.

Users were asked to log in at least once daily, and received a daily reminder e-mail. This process was supported by a log of all previous changes, a web-log for online discussions between members and comments fields which allowed members to offer supporting arguments for their choices. Usage data was recorded throughout the process and users completed an online questionnaire probing their impressions of the development process and the AAP after each 1-week period.

\section{Plan Amalgamation}

Subsequent to the Wiki process, investigators analyzed the 3 final AAPs for features in common, and applied a series of rules to develop a single AAP consisting of elements common to each plan (fig. 2).

\section{Human Factors Correction}

Human factors engineers apply knowledge of human capabilities and limitations in order to optimize the design of products, processes and/or systems with a human interface. Application of human factors engineering to design improves ease of use, reliability and user satisfaction, while reducing usage errors, user stress, user fatigue and tool liability. Both human factors engineering experts on our research team have industrial engineering training, (although hardware human factors design experts often have mechanical engineering training, while software experts may also have computer science training).

Our expert team members analyzed the final AAP and optimized visual design features according to best literature where possible, using design experience where such literature was not available. Evidence-based 'reader-friendly' design specifications included bold typeface rather than capitals or underlining for emphasis in the body of the text, increased line-spacing with larger fonts, a maximum of 70 characters per line, ragged rather than justified right margins and ample margins $[15,21]$.

\section{Face Validation}

This AAP underwent face validation in three 1-hour moderated focus groups consisting of a total of 2 pulmonologists, 2 asthma educators, 2 patients and 2 PCPs, sampled purposely to reflect both academic and community practice settings. These participants had not been exposed to the development process. The only inclusion criterion for patients was a self-reported phy- 


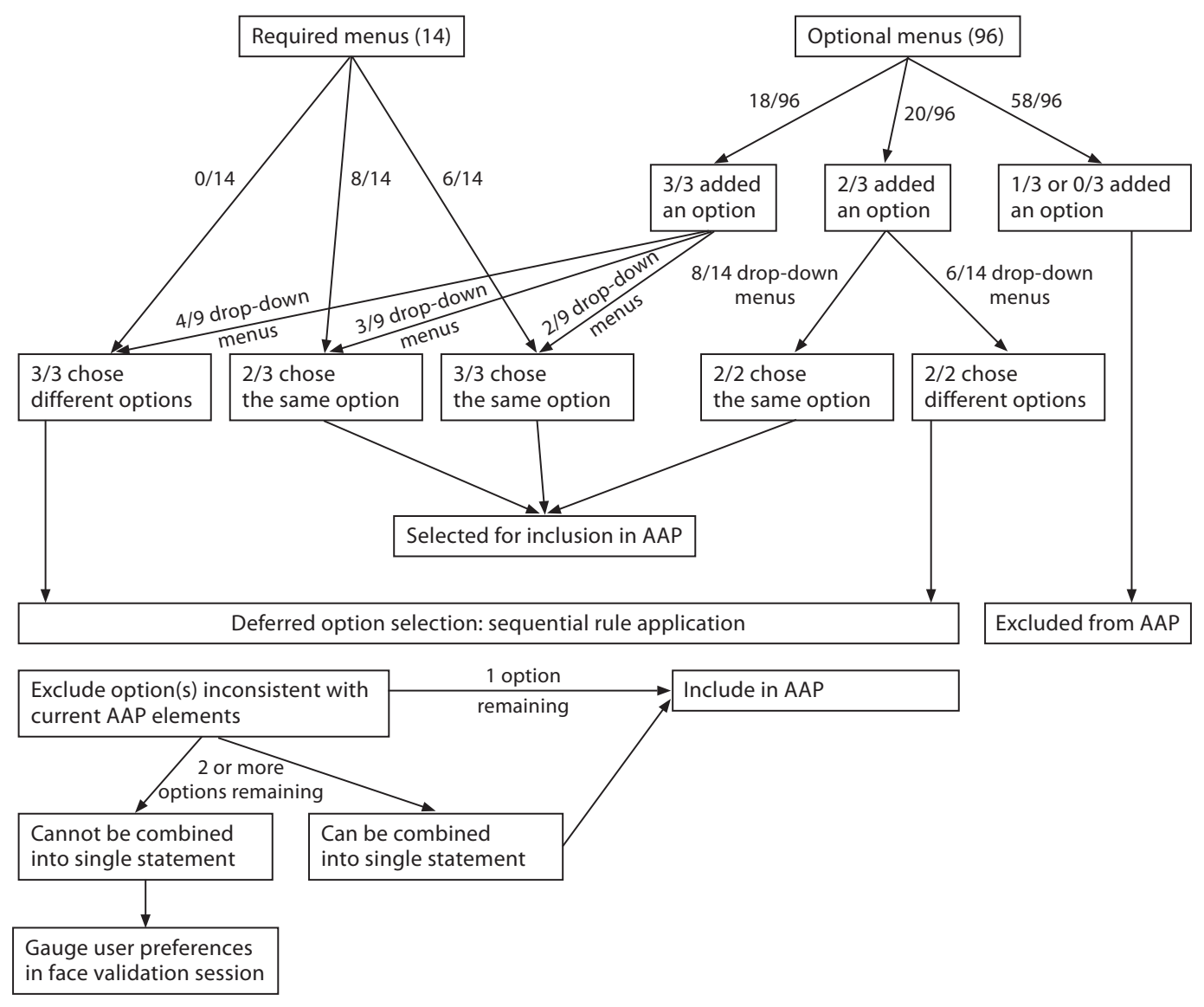

Fig. 2. This figure demonstrates the process used to amalgamate the 3 final AAPs. First, we considered "required menus" (14 menus, mean 3.2 options/menu), consisting of options that all groups had to choose between (e.g. font choice). When $2(8 / 14)$ or all 3 groups (6/14) chose the same menu option, this option was selected for the final AAP. Next, we considered "optional menus" (96 menus), consisting of options that did not necessarily have to be added to the AAP (e.g. adding "cough" in the yellow zone). Menus from which 2 (20/96), or all 3 groups (18/96) included an option would be represented in the final AAP. Considering only drop-down menus (eliminating menus that had only a Yes/No option and those consisting of additive "radio button" choices), there were 9 drop-down menus from which all 3 groups added an option (mean of 8.1 options/menu). Options chosen by $2(3 / 9)$ and all 3 groups (2/9) were selected for the AAP; option selection was

sician diagnosis of asthma. Sessions were audio-recorded and the tapes transcribed verbatim. Each session was scripted and began with background on AAPs and the purpose of the study, followed by a mock clinical encounter with role-playing. Each asthma educator completed an AAP for a patient, while each pulmonologist completed an AAP for a PCP. In a group debriefing session, deferred for menus in which each group chose a different option (4/9). Similarly, there were 14 drop-down menus from which 2 of 3 groups added an option (mean of 4.3 options/ menu). Options chosen by both groups (8/14) were selected for the AAP; option selection was deferred for menus in which each group chose a different option (6/14). We then addressed deferred option selections by employing sequential rules. First, we eliminated any option(s) that was/were inconsistent (repetitive/contradictory) with elements already in the AAP. If 2 or more options remained, in cases where they were non-contradictory and could be combined without adding a new line of text to the AAP, we combined them into a single statement which was included. Where this was not possible, we gauged user preferences in the face validation session and selected an option accordingly.

participants commented on the usability of the AAP and their satisfaction with format and content. Participants were reimbursed for their time. We analyzed focus group transcripts to ensure face validity of the AAP and finalized any option selections that had been deferred, based on feedback in face validation sessions. 
Table 1. Characteristics of HCP participants

\begin{tabular}{|c|c|c|}
\hline & $\begin{array}{l}\text { Development } \\
\text { stage }(11)^{\mathrm{a}}\end{array}$ & $\begin{array}{l}\text { Wiki } \\
\text { stage }(18)^{\mathrm{b}}\end{array}$ \\
\hline Male & $7(64)$ & $11(61)$ \\
\hline \multicolumn{3}{|l|}{ Age, years } \\
\hline$<30$ & 0 & 0 \\
\hline $30-39$ & $7(64)$ & $4(22)$ \\
\hline $40-49$ & $3(27)$ & $10(56)$ \\
\hline $50-59$ & $1(9)$ & $4(22)$ \\
\hline$\geq 60$ & 0 & 0 \\
\hline $\begin{array}{l}\text { Average number of years in practice } \\
\text { (SD) }\end{array}$ & $9(9)$ & $16(8)$ \\
\hline \multicolumn{3}{|l|}{ Practice location } \\
\hline Suburban ${ }^{\mathrm{c}}$ & $1(9)$ & $1(6)$ \\
\hline Urban $^{c}$ & $10(91)$ & $16(89)$ \\
\hline Mixed & 0 & $1(6)$ \\
\hline \multicolumn{3}{|l|}{ Practice type } \\
\hline Group & $9(82)$ & $14(78)$ \\
\hline Solo & $2(18)$ & $4(22)$ \\
\hline \multicolumn{3}{|l|}{ Practice setting } \\
\hline Academic & $8(73)$ & $11(61)$ \\
\hline Community & $3(27)$ & $7(39)$ \\
\hline $\begin{array}{l}\text { Average number of patients with } \\
\text { asthma seen each month (SD) }\end{array}$ & $20(23)$ & $52(30)$ \\
\hline Prior experience preparing an AAP & $5(46)$ & $16(89)$ \\
\hline
\end{tabular}

Numbers in parentheses are percentages unless indicated otherwise.

a Data available from HCPs included certified asthma educators (3), primary care physicians (4) and pulmonologists (4).

b Data available from HCPs included certified asthma educators (5), primary care physicians (5) and pulmonologists (8).

${ }^{c}$ Urban centers were defined as those having a population $>1,000$ people and $\geq 400$ people $/ \mathrm{km}^{2}$; less densely populated regions were considered suburban.

\section{Results}

\section{Development Stage}

We recruited 11 HCPs (3 asthma educators, 4 PCPs and 4 pulmonologists) and 5 patients for system testing in the development stage. Participant background information is provided in tables 1 and 2. Feedback and corresponding changes made to content and format options are listed in the online supplementary file 2 .

\section{Wiki Stage}

We recruited 20 HCPs (5 asthma educators, 6 PCPs and 9 pulmonologists) and 21 patients for the Wiki stage (tables 1 and 2). HCPs participating in this stage were from 16 cities, 5 Canadian provinces (Ontario, Quebec,
Table 2. Characteristics of patient participants

\begin{tabular}{|c|c|c|}
\hline & $\begin{array}{l}\text { Develop- } \\
\text { ment } \\
\text { stage (5) }\end{array}$ & $\begin{array}{l}\text { Wiki } \\
\text { stage } \\
(21)\end{array}$ \\
\hline Male & $2(40)$ & $3(14)$ \\
\hline \multicolumn{3}{|l|}{ Age, years } \\
\hline$<30$ & 0 & $3(14)$ \\
\hline $30-39$ & 0 & $6(29)$ \\
\hline $40-49$ & $1(20)$ & $4(19)$ \\
\hline $50-59$ & $3(60)$ & $5(24)$ \\
\hline$\geq 60$ & $1(20)$ & $3(14)$ \\
\hline \multicolumn{3}{|l|}{ Level of education } \\
\hline High school & $1(20)$ & $2(10)$ \\
\hline College/trade school & $1(20)$ & $10(48)$ \\
\hline University & $3(60)$ & $9(43)$ \\
\hline \multicolumn{3}{|l|}{ Current asthma follow-up } \\
\hline No regular follow-up & $1(20)$ & $10(48)$ \\
\hline Primary care physician & $2(40)$ & $9(43)$ \\
\hline Pulmonologist & $1(20)$ & $1(5)$ \\
\hline Both & $1(20)$ & $1(5)$ \\
\hline \multicolumn{3}{|l|}{ Current asthma medications } \\
\hline Short-acting bronchodilator & $5(100)$ & $18(86)$ \\
\hline Inhaled corticosteroid alone & 0 & $4(19)$ \\
\hline $\begin{array}{l}\text { Long-acting bronchodilator and } \\
\text { inhaled corticosteroid }\end{array}$ & $5(100)$ & \\
\hline Leukotriene receptor antagonist & $1(20)$ & $\begin{array}{l}0(50) \\
1(5)\end{array}$ \\
\hline \multicolumn{3}{|l|}{ Current asthma control $^{\mathrm{a}}$} \\
\hline Had exercise limitation due to asthma & $2(40)$ & $12(57)$ \\
\hline Had work absenteeism due to asthma & $1(20)$ & $4(22)^{b}$ \\
\hline $\begin{array}{l}\text { Had rescue short-acting bronchodila- } \\
\text { tor requirements }>3 \text { times per week }\end{array}$ & $1(20)$ & $10(48)$ \\
\hline Had asthma symptoms $>3$ days per week & $1(20)$ & $10(48)$ \\
\hline Had asthma symptoms $\geq 1$ night per week & $1(20)$ & $14(67)$ \\
\hline $\begin{array}{l}\text { Had an emergency room visit for asthma } \\
\text { (in the last } 12 \text { months) }\end{array}$ & $1(20)$ & $3(14)$ \\
\hline Ever received an AAP & $2(40)$ & $1(5)$ \\
\hline
\end{tabular}

Numbers in parentheses are percentages unless indicated otherwise.

${ }^{a}$ In the last 1 month unless indicated otherwise.

b Three patients were not working at the time, therefore the denominator used for this percentage calculation was 18 .

Manitoba, Alberta, British Columbia) and 3 countries (Canada, USA, Australia).

A mean of 646 changes were made to the AAP template in each week. The website was used actively for a cumulative mean of $28.8 \mathrm{~h}$ per week (all users). Each pulmonologist, PCP, asthma educator and patient logged in for a mean of 14, 16, 37 and 24 minutes per day, respectively, and made a mean of $6.3,6.0,7.2$ and 8.8 changes to the AAP per day, respectively. Of all selections, $23.4 \%$ related to AAP format, and $76.6 \%$ to content. Pulmonolo- 


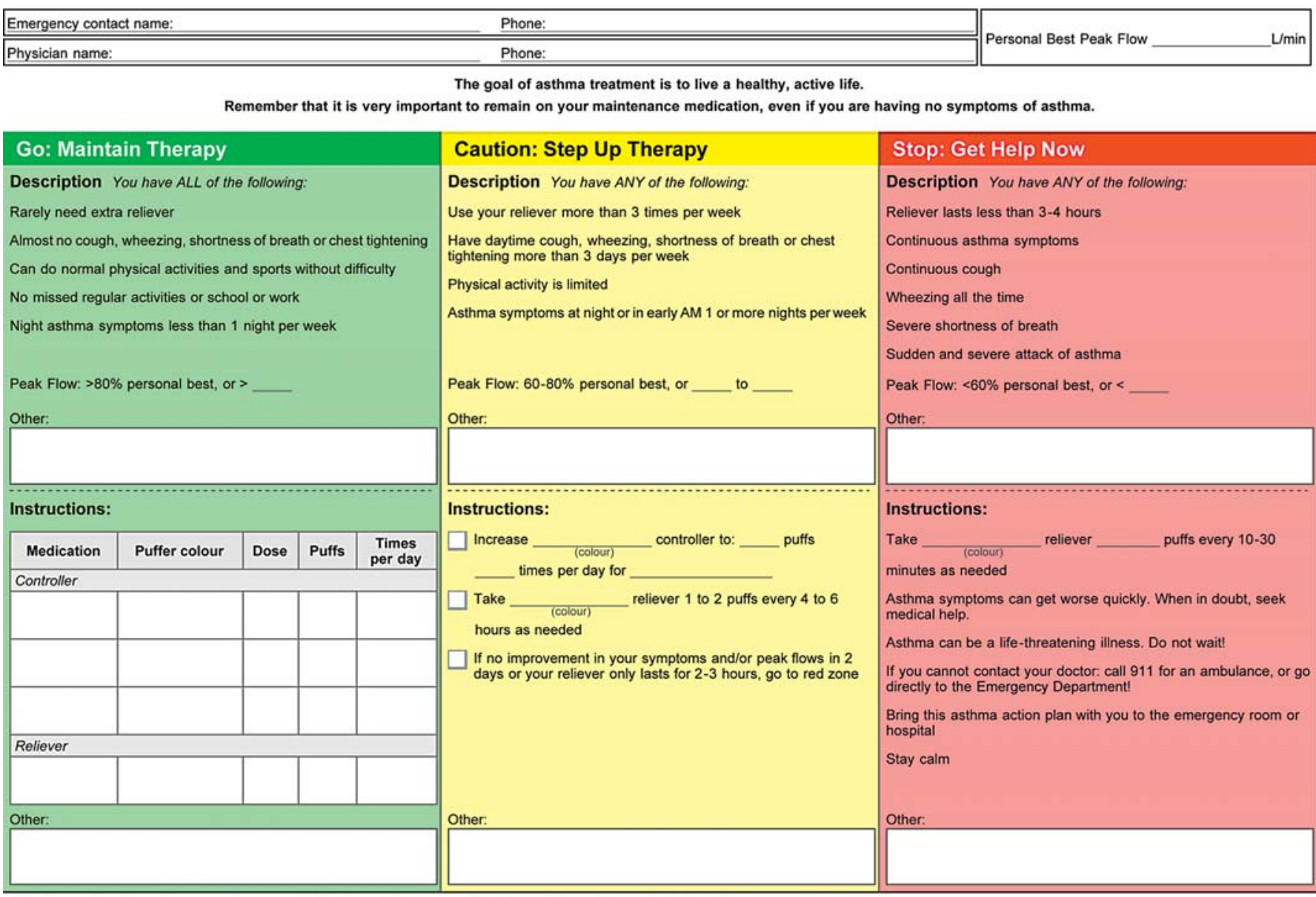

Allergies may be triggering your asthma - avoid the things that you are allergic to and have allergy skin testing if you are unsure.

Controller: has a lasting effect, treats inflammation, prevents asthma attacks, may take time to act

St. Michael's

Reliever: rapidly relieves symptoms of cough, wheeze, lasts 4 hours

Inspired Care. Inspiring Science.

Fig. 3. Final AAP. Copyright by Dr. Samir Gupta, St. Michael's Hospital. Available for download for clinical use in online suppl. file 6.

gists were more likely to make format-related changes (representing 27.2\% of changes made by that group) than patients (25.6\%), asthma educators (21.2\%) or PCPs (8.1\%) were. Eighty-three percent of participants were satisfied with the final format of the AAP, 74\% with the final content and $80 \%$ with the overall AAP. Ninety-one percent indicated that they would be able to use the AAP that was created and $77 \%$ believed that the Wiki approach was an effective way to design the AAP.

\section{Plan Amalgamation}

AAPs developed by each Wiki group are presented in online supplementary files 3-5. All 3 plans shared the same basic layout (3 zones and landscape orientation). Numerical data for 1st-order menus is presented in figure 2 (excludes 2 nd- to 4 th-order menus, which did not appear until a specific choice was made in a higher order menu). Considering both required and optional menus, selections relating to $100 / 110$ (91\%) menus and options were common to either $2 / 3$ or all 3 groups. The remaining $10 / 110$ (9\%) option selections required the application of sequential rules (fig. 2). The final AAP is shown in figure 3 (also available for download for clinical use in online suppl. file 6). 


\section{Face Validation}

All participants successfully completed the AAP. No major concerns regarding AAP format, content or usability were raised, and all participants indicated that they could use it in practice.

\section{Discussion}

We used a unique Wiki-based methodology to develop an adult AAP with input from all relevant stakeholder groups, at the same time incorporating user preferences for its visual design.

Previous AAP development processes have not consistently included all stakeholders, nor considered their design preferences [10]. Ducharme and Bogal [22] identified published AAPs that had undergone a formal development or validation process, and concluded that most AAPs recommended by national guidelines, and those tested in RCTs were developed ad hoc without a formal development process. Among 3 AAPs with published development processes, 1 was designed by experts based on evidence and 2 based on evidence and survey data from asthma educators; all 3 were revised based on patient feedback. None included the physicians that would most commonly be expected to deliver the AAP (i.e. primary care physicians) [23], all 3 focused on AAP content and none included human factors experts or specifically sought user-input on design features [22, 24]. Our development process differed from previously reported processes in 4 important ways: (1) it incorporated the preferences of all relevant stakeholder groups (including PCPs), (2) it specifically addressed design and format (through best evidence, human factors engineering experts and participant preferences), (3) it enabled members from each stakeholder group to interact and (4) the AAP was collaboratively designed by all stakeholders, rather than by a group of experts who then incorporated the suggestions of other stakeholders. These design features may have improved the validity, applicability and expected uptake of our AAP, compared to existing ones.

The inclusion of all stakeholders in the development process for various tools, particularly medical communication tools, has been shown to improve their quality and subsequent uptake [11-14]. Given that an AAP's acceptability to each user group is a function of group values, informational needs and preferences $[9,17]$, intrinsic barriers related to both AAP delivery by HCPs and AAP usage by patients may have been partly addressed by enabling these stakeholders to develop the AAP. For exam- ple, in our AAP, HCPs were able to specify 'pre-formatted' [22] statements for commonly used information and instructions, resulting in a tool that can be efficiently individualized in practice by entering checkmarks and filling in blanks, rather than requiring 'free-text' composition. By choosing particular statements, HCPs also inherently addressed areas in which they perceived the greatest need for decision support [22]. PCPs have indicated that such 'user-friendly' features could increase their likelihood of delivering AAPs [25] by addressing two important delivery barriers: a lack of time and a lack of practitioner confidence $[3,5-8,26]$.

Qualitative studies suggest that patients also have specific preferences for AAPs, including smaller and less detailed plans [9]. Furthermore, patient illness perspectives, symptom experiences and interpretation of instructions may differ fundamentally from what is projected by HCPs $[10,27]$. Accordingly, including the patient perspective in AAP development may improve comprehensibility and clarity, thereby improving patient confidence in AAP use [10]. For example, our AAP features an area to indicate the color of each inhaler - a patient-friendly feature which addresses confusion between reliever and controller medications [28].

User preferences for layout, design and visual appeal as well as simple typological features have been shown to impact the uptake and effectiveness of asthma-related printed educational materials [17] and other visual media-based health care interventions such as evidencebased order sets [16], educational posters [29] and medical decision aids [30]. Accordingly, we ensured that format options for our AAP adhered to human factors design evidence and expert recommendations. For example, we addressed 'document literacy' [21] (readability of graphs and tables) by including several options for zone layout displays and coloring, and 'quantitative literacy' [21] (ability to process numbers and to perform calculations) by providing an option to display medication doses and frequencies in a tabular format, and by providing a variety of formats to display cut-offs for frequencies of symptoms or of puffer use. We also included options to employ simple symbols ( $>$ and $<$ ), known to act as visual cues that render data more readily evaluable and reduce the reader's cognitive load [31]. Format was important to users, with $23.4 \%$ of selections being format-related. Furthermore, pulmonologists made the greatest proportion of format selections, suggesting that content experts also recognize the importance of format.

Several other findings support the validity of our AAP. First, there was a significant similarity between the AAPs 
created by each of the 3 Wiki groups, with a majority or unanimous agreement in the handling of $91 \%$ of the menus and options. This convergent development in 3 unique user groups suggests that most stakeholders have similar overarching goals and preferences and that our process captured and represented these effectively. Usage data indicate that users were engaged in the development process, and most felt that the Wiki process was an effective design strategy. Users also expressed a high level of satisfaction with format, content and overall composition of the final AAP, with 91\% indicating that they would be able to use it. Face validity testing confirmed that the final AAP was acceptable and usable in a naive set of users. Finally, our AAP fulfils 3 sets of validity criteria derived through discrete methodologies. In their prospective AAP development study, Ducharme et al. [24] identified environmental control, adherence to treatment, self-assessment and self-management, regular follow-up and asthma education as key concepts. In their review of AAPs tested in prior RCTs, Gibson and Powell [32] identified when, how and for how long to increase treatment and when to seek medical help as 'key components' of a 'complete AAP'. In their review of best evidence and expert opinion, Rank et al. [33] recommended including 2-4 action points, a brief description of treatment increase, a description of how long to increase treatment, instructions on when to obtain additional advice and physician contact information in all AAPs.

The diversity of our study population suggests a broad applicability of our AAP. We recruited professionals and patients from both academic and community settings, and our method enabled us to recruit HCPs from various geographical locations; those in the Wiki stage were from both group and solo practices and were highly experienced. Distribution of medications and symptoms among patients suggests a wide range of disease severity. Consistent with the overall asthma population, most patients were followed in primary care exclusively [23], and most had not previously received an AAP [3]. However, most HCPs were from urban centers, which might limit generalizability to rural practice environments, and most patients were female, raising a concern due to possible gender biases in AAP preferences. Furthermore, patient inclusion criteria included basic IT skills and regular access to computers, biasing towards a high level of education and likely towards a higher socioeconomic class. However, previous studies have suggested that the majority of patients with asthma are computer literate and have access to the internet [34], and patient willingness to use web technologies does not appear to be asso-

Online Asthma Action Plan Development ciated with gender, age, education level or socioeconomic status [35].

It should also be noted that our final AAP did not include instructions to initiate oral corticosteroid therapy, as only 1 of the 3 Wiki groups decided to include this instruction in their final AAP (online suppl. file 4). Although the majority of AAPs tested in RCTs have included a recommendation to add oral corticosteroids, this remains an area of controversy in real-world practice. In a review of 17 AAPs used in RCTs, Gibson and Powell [32] found that a recommendation to both increase inhaled steroids and to add oral steroids was beneficial when compared to usual care (no action plan). However, they acknowledged that they were unable to compare combination therapy with increased inhaled corticosteroids alone. Together with other authors, they have also noted that although the need for oral corticosteroids is well established in severe exacerbations, evidence for their use in the mild asthma 'worsenings' targeted by AAPs is lacking [36]. Furthermore, there is some evidence that an increase in the inhaled corticosteroid dose alone may have an effect comparable to oral corticosteroids [37], and may effectively avert a full blown exacerbation [38, 39]. Given potential toxicities, clinicians may also have concerns regarding inappropriate self-administration of oral corticosteroids, and may prefer to discuss symptoms with patients before providing this prescription. In patients who may have a more predictable course and reliable selfmanagement discipline, clinicians can choose to add instructions for oral corticosteroid use in the 'other' section of the yellow and/or red zones in our action plan.

We acknowledge several limitations. Cultural sensitivity of health information may be a determinant of patient uptake [40], and we did not tailor our AAP to recipients of specific cultural backgrounds. Future cultureand language-specific AAPs could be developed by undertaking a distinct Wiki process with members of each cultural group. The uptake of our AAP may also be limited in populations with impaired literacy, including marginalized and immigrant populations where pictorial AAPs may be more effective [26]. Our consensus approach did not require evidence of the impact on health outcomes for each feature included in the AAP. However, few prior studies have successfully identified individual AAP features associated with effectiveness [22]. The only feature that has been compared directly in RCTs is the use of a peak-flow- versus a symptom-based zone description, with the results of 5 RCTs being too inconsistent to indicate a superior choice [41]. Given the practical limitations of both prospective and retrospective evidence- 
based approaches to identifying even key AAP features $[22,32,42]$, we believe that our consensus approach was justified. Finally, the uptake and effects of our AAP have not yet been formally tested in a clinical setting. However, this is the case for the majority of AAPs that are currently in use and most of those did not undergo a formal development process.

\section{Conclusions}

We have developed an AAP through a rigorous methodology that included all relevant stakeholders and considered user preferences, the best evidence and expert opinion not only for content, but also for appearance and usability. Our systematic development process and results would favor this AAP over most existing AAPs for clinical implementation. We do plan to measure realworld uptake and impact on health outcomes in order to further validate both the AAP and our novel development methodology.

\section{Acknowledgements}

This work was supported by the Physicians' Services Incorporated Foundation and the Bell University Labs. The funders played no role in the design of the study, the collection, analysis and interpretation of data, the writing of the manuscript or the decision to submit the manuscript for publication. We would like to thank Dr. Mark Chignell, Dr. Onil Bhattacharya, Dr. Francine M. Ducharme, Dr. Andreas Laupacis, Dr. Diane Lougheed, Dr. Ann Mckibbon, Ms. Carole Madeley, Mr. David Newton and Ms. Maria Wowk for their assistance in planning and executing this study. We would also like to thank all study participants for their valuable time.

\section{References}

1 Gibson PG, Coughlan J, Wilson AJ, Abramson M, Bauman A, Hensley MJ, Walters EH: Self-management education and regular practitioner review for adults with asthma. Cochrane Database Syst Rev 2000; 2:CD001117.

2 Expert Panel Report 3: guidelines for the diagnosis and management of asthma; in: $\mathrm{Na}$ tional Asthma Education and Prevention Program. National Institutes of Health, National Heart, Lung and Blood Institute, 2007.

3 FitzGerald JM, Boulet LP, McIvor RA, Zimmerman S, Chapman KR: Asthma control in Canada remains suboptimal: the Reality of Asthma Control (TRAC) study. Can Respir J 2006; 13:253-259.

4 van der Palen J, Klein JJ, Zielhuis GA, van Herwaarden CL, Seydel ER: Behavioural effect of self-treatment guidelines in a selfmanagement program for adults with asthma. Patient Educ Couns 2001;43:161-169.

5 Moffat M, Cleland J, van der Molen T, Price D: Poor communication may impair optimal asthma care: a qualitative study. Family Practice 2007;24:65-70.

6 To T, McLimont S, Wang C, Cicutto L: How much do health care providers value a community-based asthma care program? A survey to collect their opinions on the utilities of and barriers to its uptake. BMC Health Services Res 2009;9:77.

7 Labelle M, Beaulieu M, Renzi P, Rahme E, Thivierge RL: Integrating clinical practice guidelines into daily practice: impact of an interactive workshop on drafting of a written action plan for asthma patients. I Contin Educ Health Prof 2004;24:39-49.

-8 Partridge MR: Written asthma action plans. Thorax 2004;59:87-88.
-9 Fishwick D, D’Souza W, Beasley R: The asthma self-management plan system of care: what does it mean, how is it done, does it work, what models are available, what do patients want and who needs it? Patient Educ Couns 1997;32:S21-S33.

10 Douglass J, Aroni R, Goeman D, Stewart K, Sawyer S, Thien F, Abramson M: A qualitative study of action plans for asthma. BMJ 2002;324:1003-1007.

11 Keown K, Van Eerd D, Irvin E: Stakeholder engagement opportunities in systematic reviews: knowledge transfer for policy and practice. J Contin Educ Health Prof 2008;28:67-72.

12 The AGREE Collaboration: Appraisal of guidelines for research \& evaluation (AGREE) instrument. http://www.agreecollaboration.org/.

13 Vastine A, Gittelsohn J, Ethelbah B, Anliker J, Caballero B: Formative research and stakeholder participation in intervention development. Am J Health Behav 2005;29:57-69.

14 Nilsen ES, Myrhaug HT, Johansen M, Oliver S, Oxman AD: Methods of consumer involvement in developing healthcare policy and research, clinical practice guidelines and patient information material. Cochrane Database Syst Rev 2006;3: CD004563.

15 Mayberry JF: The design and application of effective written instructional material: a review of published work. Postgraduate Med J 2007;83:596-598.

16 Reingold S, Kulstad E: Impact of human factor design on the use of order sets in the treatment of congestive heart failure. Acad Emerg Med 2007;14:1097-1105.
17 Bauman A: The comprehensibility of asthma education materials. Patient Educ Couns 1997;32(1 suppl):S51-S59.

18 Murphy MK, Black NA, Lamping DL, McKee CM, Sanderson CF, Askham J, Marteau $\mathrm{T}$ : Consensus development methods, and their use in clinical guideline development. Health Technol Assess 1998;2:i-iv.

19 Bruseberg A, McDonagh-Philp D: Focus groups to support the industrial/product designer: a review based on current literature and designers' feedback. Appl Ergon 2002; 33:27-38.

20 Gupta S, Wan F, Newton D, Bhattacharyya O, Chignell M, Straus S: WikiBuild: a new online collaboration process for multistakeholder tool development and consensus building. J Med Internet Res 2011;13:e108.

21 Root J, Stableford S: Easy-to-read consumer communications: a missing link in Medicaid managed care. J Health Polit Policy Law 1999;24:1-26.

22 Ducharme FM, Bhogal SK: The role of written action plans in childhood asthma. Curr Opin Allergy Clin Immunol 2008;8:177-188.

23 Global Asthma Physician and Patient Survey. http://www.gappsurvey.org/media-keyfindings.html.

24 Ducharme FM, Noya F, McGillivray D, Resendes S, Ducharme-Benard S, Zemek R, Bhogal SK, Rouleau R: Two for one: a selfmanagement plan coupled with a prescription sheet for children with asthma. Can Respir J 2008;15:347-354.

25 Bibb SC, Norwood R, Meyer JF: Factors associated with health care professionals choice of written asthma management plans. Mil Med 2007;172:1058-1064. 
26 Roberts NJ, Mohamed Z, Wong P-S, Johnson M, Loh L-C, Partridge MR: The development and comprehensibility of a pictorial asthma action plan. Patient Educ Couns 2009;74:12-18

-27 Ring N, Jepson R, Hoskins G, Wilson C, Pinnock $\mathrm{H}$, Sheikh A, Wyke S: Understanding what helps or hinders asthma action plan use: a systematic review and synthesis of the qualitative literature. Patient Educ Couns 2011;85:131-143.

28 Chapman KR, Ernst P, Grenville A, Dewland P, Zimmerman S: Control of asthma in Canada: failure to achieve guideline targets. Can Respir J 2001;8(suppl A):35A-40A.

29 Thomas M, Gillespie W, Krauss J, Harrison S, Medeiros R, Hawkins M, Maclean R, Woeltje KF: Focus group data as a tool in assessing effectiveness of a hand hygiene campaign. Am J Infect Control 2005;33:368-373.

30 Holmes-Rovner M, Stableford S, Fagerlin A, Wei JT, Dunn RL, Ohene-Frempong J, KellyBlake K, Rovner DR: Evidence-based patient choice: a prostate cancer decision aid in plain language. BMC Med Inf Decis Mak 2005;5: 16.
1 Hibbard JH, Peters E: Supporting informed consumer health care decisions: data presentation approaches that facilitate the use of information in choice. Annu Rev Public Health 2003;24:413-433.

32 Gibson PG, Powell H: Written action plans for asthma: an evidence-based review of the key components. Thorax 2004;59:94-99.

33 Rank MA, Volcheck GW, Li JTC, Patel AM, Lim KG: Formulating an effective and efficient written asthma action plan. Mayo Clin Proc 2008;83:1263-1270.

34 Bussey-Smith KL, Rossen RD: A systematic review of randomized control trials evaluating the effectiveness of interactive computerized asthma patient education programs. Ann Allergy Asthma Immunol 2007;98:507516.

35 Fonseca JA, Costa-Pereira A, Delgado L, Fernandes L, Castel-Branco MG: Asthma patients are willing to use mobile and web technologies to support self-management. Allergy 2006;61:389-390.

36 Balter M, Ernst P, Watson W, Kim H, Cicutto L, Beauchesne M-F, Cave AJ, Kaplan A, Hogg D, McIvor A, et al: Asthma worsenings: approaches to prevention and management from the Asthma Worsenings Working Group. Can Respir J 2008;15(suppl B):1B19B.
37 Gibson P: Corticosteroids - clinical applications: exacerbations of asthma in adults. Austr Prescr 1996;19:44-47.

38 Oborne J, Mortimer K, Hubbard RB, Tattersfield AE, Harrison TW: Quadrupling the dose of inhaled corticosteroid to prevent asthma exacerbations: a randomized, double-blind, placebo-controlled, parallelgroup clinical trial. Am J Respir Crit Care Med 2009;180:598-602.

39 Foresi A, Morelli MC, Catena E: Low-dose budesonide with the addition of an increased dose during exacerbations is effective in long-term asthma control. On behalf of the Italian Study Group. Chest 2000;117:440446.

40 Thomson MD, Hoffman-Goetz L: Readability and cultural sensitivity of web-based patient decision aids for cancer screening and treatment: a systematic review. Med Inform Internet Med 2007;32:263-286.

41 Toelle BG, Ram FS: Written individualised management plans for asthma in children and adults. Cochrane Database Syst Rev 2002, 3.

42 Zemek RL, Bhogal SK, Ducharme FM: Systematic review of randomized controlled trials examining written action plans in children: what is the plan? Arch Pediatr Adolesc Med 2008;162:157-163. 